\title{
Spinal Cord Schistosomiasis: A Case Report and Review of the Literature
}

\author{
I. Suchet, B.Sc. (Hons.), M.B.B.Ch. (Wits.), ${ }^{1}$ C. Klein, M.B.Ch.B., \\ F.C.P. (S.A.), ${ }^{2}$ T. Horwitz, M.B.B.Ch (Wits.), S. Lalla, M.B.B.S (Mysore \\ University), ${ }^{4}$ M. Doodha, M.B.B.S. (Bombay University) ${ }^{5}$ \\ ${ }^{1}$ Senior House Officer, Department of Neurology, ${ }^{2}$ Consultant Neurologist, \\ Department of Neurology, ${ }^{3}$ Registrar, Department of Radiology, ${ }^{4}$ Medical Officer, \\ Department of Radiology, ${ }^{5}$ Senior Medical Officer, Department of Urology, Bara- \\ gwanath Hospital and University of the Witwatersrand, South Africa
}

\section{Summary}

Spinal cord involvement by Schistosomiasis is considered to be rare. We report a case of acute transverse myelitis due to Schistosoma mansoni in which treatment with praziquantal and steroids was started three days after the onset of a paraparesis, with complete neurological recovery.

Key words: Spinal cord disease; Schistosomiasis

\section{Introduction}

Schistosomiasis is considered to be a rare cause of an acute transverse myelitis. However, the true incidence of the disease is unknown, as it is rarely diagnosed and even more rarely treated effectively during life (Bird, 1964; El-Banhawy, 1971; Barnett, 1965), the diagnosis usually being made at autopsy. Symptomatic and asymptomatic nervous system involvement, particularly of the spinal cord, is probably more common than suspected, considering the striking infestation rates in endemic areas, and the estimate that about 200 million people throughout the world are infected with schistosomiasis (World Health Organization, 1965).

\section{Case report}

A 19-year-old male was admitted for investigation of recurrent acute urinary tract infections. A previous history of terminal haematuria, as well as a history of swimming in rivers while on holiday in an endemic schistosomiasis region 1 year and again just prior to admission, was obtained. Symptoms and signs of a urinary tract infection were present on admission, and a Klebsiella species was cultured from the urine and successfully treated. No parasite ova were found on urine microscopy. The serum leukocyte count was $14200 / \mathrm{mm}^{3}$ with $60 \%$ 
neutrophils and 3\% eosinophils. Following treatment an excretory urogram demonstrated features consistent with chronic pyelonephitis and chronic cystitis. A subsequent bladder biopsy revealed viable ova of Schistosoma mansoni.

While still under investigation, the patient developed an acute spastic paraparesis (grade $3 / 5$ power in an upper motor neurone distribution), and a sensory level from T10 to all modalities, with retained bladder and bowel function. A myelogram was performed and it was normal, but the cerebrospinal fluid had a raised protein $(1.2 \mathrm{mmol} /$ litre $)$, normal glucose and chloride values, and 68 lymphocytes.

Viral Studies, stains and cultures for tuberculosis and fungi were negative. The Fluorescent Treponemal Antibody Test, Reactive Precipitin Reagen, and antinuclear factor were negative in the blood and cerebrospinal fluid.

The bilharzia enzyme linked immunosorbent assay (Elisa), Radio-Immunoassay and fluorescent antibody tests in the cerebrospinal fluid and serum were all positive. In view of these results treatment was started on the third day following the onset of paraparesis with praziquantal $(50 \mathrm{mg} / \mathrm{kg} / \mathrm{day}$ ) for three days and prednisone $50 \mathrm{mg} /$ day for the first week and then slowly withdrawn over four weeks (i.e., $40 \mathrm{mg} /$ day on week two, $30 \mathrm{mg}$ /day on week three, 20 $\mathrm{mg}$ /day on week four and $10 \mathrm{mg}$ /day on week 5). On the seventh day of treatment the motor and sensory deficit began to improve. He was discharged from hospital after 6 weeks without any residual neurological deficit, and normal cerebrospinal fluid (Table I).

Table I Cerebrospinal fluid and blood parameters

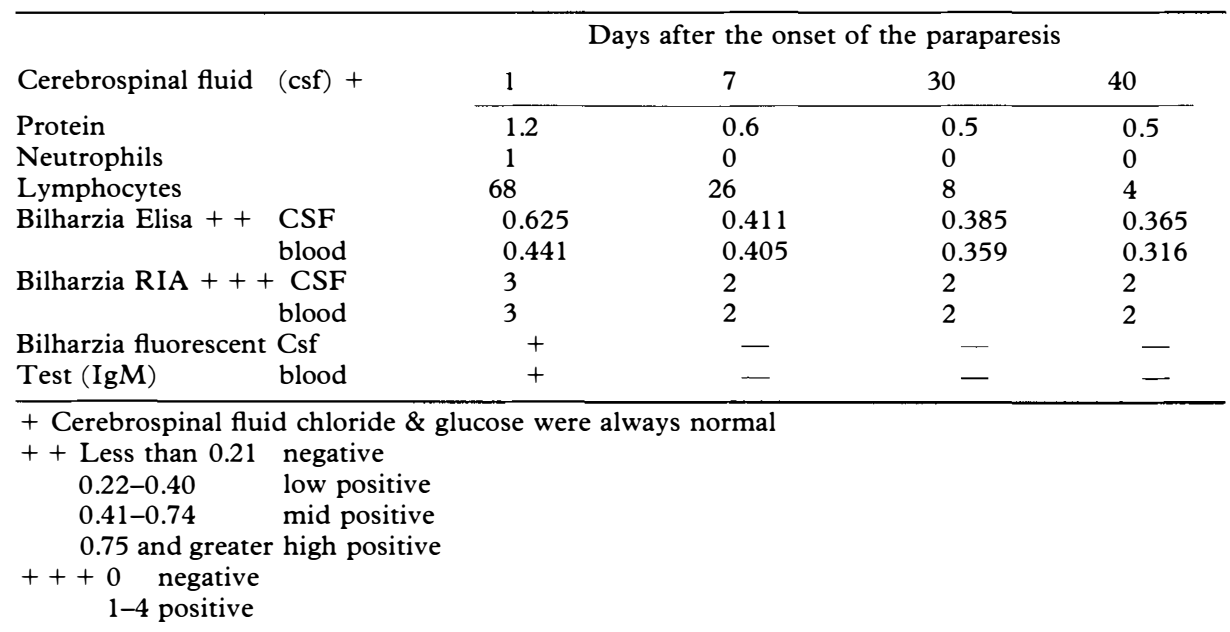

\section{Discussion}

Since the first report of spinal cord involvement by Schistosomiasis (Shimamura and Tsunoda, 1906), there have been numerous reviews of the literature. Herskawitz (1972) found 104 cases of central nervous system schistosomiasis, 25 of which were limited to the spinal cord. Norfray (1978) found 43 cases of spinal schistosomiasis in the world literature.

To date we have found 64 cases reported in the literature (Table II) (Norfray, 
Table II The total number of reported cases of spinal schistosomiasis, the types of organisms involved in the various modes of presentations, and the sex ratio

\begin{tabular}{|c|c|c|c|c|c|c|c|c|}
\hline \multirow[b]{3}{*}{ Type } & \multicolumn{8}{|c|}{ Modes of presentation } \\
\hline & Number of & & & & Anterior spinal & & Sex & ratio \\
\hline & cases & Granuloma & Myelitis & Radiculitis & antery occlusion & Unknown & Male & Female \\
\hline S. Mansoni & 41 & 16 & 19 & 0 & 1 & 5 & 34 & 7 \\
\hline S. Haematobium & 13 & 5 & 6 & 2 & 0 & 0 & 10 & 3 \\
\hline $\begin{array}{l}\text { Mixed mansoni } \\
\& \text { haematobium }\end{array}$ & 1 & 0 & 1 & 0 & 0 & 0 & 1 & 0 \\
\hline S. Japonicum & 1 & 0 & 1 & 0 & 0 & 0 & 1 & 0 \\
\hline Unspecified & 8 & 6 & 0 & 0 & 0 & 2 & 7 & 1 \\
\hline
\end{tabular}

Schlachter, Heiser, Weinberg, Jerva, Wizgird, 1978; Rosenbaum, Ishii, Tanowitz, Wittner, 1972; Neves, Marinho, De Araujo, Raso, 1973; El-Banhawy, Elwan, Tahar, 1972; Queiroz, Nucci, Facure, Facure, 1979; Dar, Zimmerman, 1977; Pool, 1978-1979; Lechtenberg, Vaida, 1977; Luyendijk, Lindeman, 1975; Wood, Srolovitz, Schetman, 1976; Saxe, Gordon, 1975; El-Banhawy, 1971; Scaff, Riva, 1971; Nozias, Pichard, Develoux, Gentilini, 1983; Chait, Gannon, 1969; Warren, 1973; Eftimiou, Denning, 1984; Adeloye, Folami. Aghadiung, 1982; Levy, 1970; Ghaly, El-Banhawy, 1973; Siddorn, 1978; Ibrahim, 1941; Sparrow, 1966; Arean, 1966; Scully, Mark, McNealy, 1985).

Spinal involvement in schistosomiasis is usually due to schistosoma haematobium or mansoni, schistosoma japonicum more commonly affects the brain. Reaction to the eggs rather than the adult worms are the cause of the major neurological syndromes, with the diversity of the host's immune response accounting for the various types of presentations (Wilcocks, Manson-Bahr, 1972; Gelfand, 1973; El-Banhawy, 1972).

In cases presenting as an Acute Transverse Myelitis, multiple small granulomata are found, each surrounding one or more ova lying together in the spinal cord (Levy, 1970). Sometimes instead of many small granulomata, a large solitary granuloma forms. It presents as an intraspinal mass lesion and appears grey and granular, closely resembling a glioma macroscopically (Cohen, Capildeo, Rose, Pallis, 1977). Unless schistosomiasis is suspected the diagnosis is only made histologically following surgical biopsy.

A third form of presentation is the radicular form, with granuloma forming around spinal roots or the cauda equina. This form is usually associated with the intra-spinal granuloma, and there is some doubt of its independent existence (El-Banhawy, 1971; Ghaly and El-Banhawy, 1973).

Finally, vascular syndromes may occur. One well documented case (Siddorn, 1978), and possibly a second (Bird, 1965), of anterior spinal artery occlusion have been reported. Lymphocytic infiltration with intimal thickening and fibrinoid degeneration of spinal vessels have been reported (Marciel-Rojas and Fiol, 1963; Maciel et al., 1954). Another possibility is that ova are disseminated, as arterial emboli from the pulmonary circulation, explaining the cases with skin (Wood et al., 1976; Saxe \& Gordon, 1975) and conjunctional (Ibrahim, 1949; Sparrow, 1966) involvement. Some authors have surmised that there is actual oviposition in situ by aberrant worms which have made their way into the vessels of the spinal cord (Jane et al., 1970; Raper, 1948). With the exception of one case no adult worms have been found inside the spinal cord. The most 
common areas of the spinal cord affected are the lower thoracic or lumbar spine. Only one case involving the cervical cord has been reported (Molyneux et al., 1978). This predilection is probably explained by the free anastomosis between the pelvic veins and the valveless vertebral plexus (Batsons Plexus) (Batson, 1940) as well as between haemorrhoidal and systemic veins.

\section{Diagnosis}

Because of the variability of presentation, a high index of suspicion should be maintained in patients presenting with spinal signs, and who live, or have visited endemic areas. Numerous consecutive urine and faecal examinations for ova should be made, as eggs are discharged intermittently, and to a less extent in chronic cases (Norfray, et al., 1978; Arean, 1966). Eosinophilia, particularly in chronic cases, may be absent. The cerebrospinal fluid is occasionally normal, but more commonly reveals a lymphocytosis and elevated protein. A raised eosinophil count has rarely been noted. Rectal, bladder or liver biopsies may be required, but highly specific non-invasive immunological tests are now available with high sensitivity and specificity (Nillyer et al., 1979; Ruiz-Tiben et al., 1979). The immunological tests used are the double diffusion test (DDT), circumvocal precipiton test (COP), enzyme linked immunosorbent assay (Elisa), radioimmuno assay (RIA). The various skin tests are outdated because of their relative insensitivity, as well as the numerous cross reactions that occur with other trematode infections. So by using both the Elisa $(92 \%$ specificity and $75 \%$ sensitivity) and RIA (79\% specificity and $95 \%$ sensitivity) in our patient, a high degree of both specificity and sensitivity was achieved.

\section{Treatment}

Praziquantal has revolutionised the treatment of schistosomiasis. It is highly effective against all three types of schistosomiasis (Kardaman et al., 1983; Pearson, 1983). Praziquantal appears to increase permeability of the plasma membrane of susceptible worms to calcium ions, resulting in a loss of intracellular calcium and contraction and paralysis of the worms (Pearson, 1983). Side effects are usually slight and include nausea, vomiting and abdominal pain. Cure rates range from $71-98^{\circ}{ }_{0}$ for schistosoma haemotobium and $66-94^{\circ}{ }_{0}$ for schistosoma mansoni. Steroids have been used with conflicting results in cases with spinal involvement, as in most reported, therapy has been delayed for at least one week after the development of an advanced deficit (Lechtenberg and Vaida, 1977). Experimental studies by Domingo et al. (1967) indicate that the size of granulomata are considerably diminished by steroids. Bird is also a proponent of steroid therapy while Colley has questioned the use of corticosteroids in acute transverse myelitis. The use of steroids to counteract the allergic inflammatory reaction plus treatment with praziquantal directed at the adult worms would seem to be a reasonable therapeutic course.

Delay in treatment as in the case of a young man who went on a 3 month trip to Kenya (Scully et al., 1985), usually results in a complete, irreversible paraplegia. Harries et al. (1986), in their controlled trial concluded that all expatriates 
returning to Britain from endemic areas in Africa who may have been exposed to infection be screened for schistosomiasis. Positive serology requires further investigation and treatment if necessary, so that tragedies may be avoided.

\section{Conclusion}

Complete neurological recovery in our patient may be explained by the early commencement of treatment with steroids and praziquantal, prior to the onset of a complete paraplegia.

Because of the extent of schistosomal endemic areas, often with high infestation rates, the increased mobility of the world's population, and the frequent assymptomatic nature of the disease, schistosomiasis should always be considered in patients, presenting with spinal lesions who may have been exposed to the infestation. Vigilance and appropriate investigation will reveal the true extent of central nervous system schistosomiasis, and clarify the possible importance of early and specific treatment nowadays.

\section{References}

Adeloye A, Folami AO, Aghadiung Pu 1982 Schistosoma haematobium granuloma of the spinal cord in a Nigerian boy. Neurochirurgia (Stuttg) 25(3):100-102.

AREAN VM Schistosomiasis-a clinico pathologic evaluation. In: SoMmERs SC (ed) 1966 Pathology Annual 1:68-126. New York, Appleton Century Crofts.

BIRD AV 1964 Acute spinal schistosomiasis. Neurology (Minneap) 14, 647-656.

BIRD AV 1965 Spinal cord complications of bilharziasis. South African Medical fournal 39:158162.

BARNETt AM 1965 Bilharzial granuloma of the spinal cord. South African Medical fournal 39:699700.

BATSON OV 1940 The function of the vertebral veins and their role in the spread of metastasis. Annals of Surgery 112:139-149.

Chait A, Gannon WE. Schistosomiasis of the spinal cord. American fournal of Roentgenology, Radiation Therapy and Nuclear Medicine, 105: 400-403.

Cohen J, CApildeo R, Rose FC, et al. 1977 Schistosomal myelopathy (letter). British Medical fournal 2(6084):1418.

Colley DG 1974 Immunologic consequences of Schistosome infection. In: BRENT L, Holborrow J (eds) 'Progress in Immunology II': Vol. IV. New York, American Elsevier, pp. 171-179.

DAR J, ZIMMERMAN RR 1977 Schistosomiosis of the spinal cord. Surgical Neurology 8:416-418.

DOMINGO EO, COWAN RBT, WARREN KS 1967 The inhibition of granuloma formation around schistosoma mansoni eggs. I Immuno suppressive drugs. American fournal of Tropical Medicine and Hygiene 16:284-292.

Eftimiou J, DenNing D 1984 Spinal cord disease due to Schistosoma mansoni successfully treated with oxanniquine. British Medical fournal 288(6427):1343-1344.

El-Banhawy A 1972 Bilharziasis of the spinal cord. Proceedings of the Fourth European Congress on Neurology 757-759.

El-Banhawy A, ElWAN O, TAher Y 1972 Bilharzial granuloma of conus medullaris and cauda equina. Paraplegia 10:172-180.

El-Banhawy A 1971 Schistosomiasis of the spinal cord, conus and cauda. Neurologia Medio Chirurggica (Tokyo) 11:17-33.

Gelfand M 1973. In: SpIllane JD (ed) Tropical Neurology. London, Oxford University Press.

Ghaly AF, El-BANHAwy A 1973 Schistosomiasis of the spinal cord. Fournal of Pathology 3:5760.

HARRIES AD, Fryatt R, WALKER J, et al. 1986 Schistosomiasis in expatriates returning to Britain from the tropics: A controlled study. Lancet 1:86-88.

HeRSKAwITZ A 1972 Spinal involvement with Schistoma mansoni. Fournal of Neurosurgery 36:494-497.

IBRAHIM KG 1941 Bilharzial granuloma of the conjunctiva. Bulletin of Opthalmic Society Egypte 34:89-91. 
JANE JA, WARREN KS, VAN DEN NOORTE S 1970 Experimental cerebral schistosoma japonicum in primates. Fournal of Neurology, Neurosurgery and Psychiatry 33:426-430.

KaRdaman MW, Amin MA, Fenwick A, et al. 1983 A field trial using Praziquantal (Biltricide) to treat Schistosoma mansoni and Schistosoma haematobin infection in Gezira, Sudan. Annals of Tropical Medicine and Parasitology 77(3):297-304.

LECHTENBERG R, VAIDA GA 1977 Schistosomiasis of the spinal cord. Neurology 27:55-59.

LEVY LF 1970 Bilhazial involvement of the central nervous system. Medical fournal of Zambia 4:191-199.

LUYENDIJK W, LINDEMAN J 1975 Schistsomiasis mansoni of the spinal cord simulating an intramedullary tumour. Surgical Neurology 4: 457-460.

Maciel Z, Coelho B, Aвath G 1954 Myelite Schistosomique due au Schistosomiasis mansoni: Etude anatomo-clinique. Revue Neurologique 91: 241-259.

MARCIAL-Rojas RA, FIOL RE 1963 Neurologic complications of Schistosomiasis: Review of literature and report of two cases of transverse myelitis due to Schistosoma mansoni. Annals of Internal Medicine 59:215-230.

Molyneux ME, Galatius Jensen F 1978 Successful drug tretment of Schistosomal myelopathy. South African Medical fournal 54:871-877.

Neves J, Marinho RP, De ARAujo PK, et al. 1973 P Spinal cord complications of acute Schistosomiasis mansoni. Transactions of the Royal Society of Tropical Medicine and Hygiene, 67: 782-792.

Nillyer GV, Ruiz-Tiben E, KNight WB, et al. 1974 Immunodiagnosis of infection with Schistosoma mansoni: Comparison of Elisa, radioimmuno assay, and precipitation tests performed with antigens from eggs. American fournal of Tropical Medicine and Hygiene 28[4]: $661 \dagger 664$.

Norfray JF, Schlachter L, Heiser WJ, et al. 1978 Schistosomiasis of the spinal cord. Surgical Neurology 9:68-71.

Nozias JP, Pichard E, Develoux M, et al. 1983 Les Localisations Ectopiques des Bilharzioses (Sauf S. Japonicum). Archives d'Anatomie et de Cytologie Pathologiques, 4: 241-245.

PEARSON RD, GuERRAND RL 1983 Praziquantal: A major advance in anthelminthic therapy. Annals of Internal Medicine 99:195-198.

Pool GM 1978-1979 Tropical paraplegia: A case of transverse myelitis, probably caused by Schistosomiasis mansoni. Paraplegia 16:113-117.

Queiroz L, Nucci A, FACURE NO, et al. 1979 Massive spinal cord necrosis in Schistosomiasis Archives of Neurology 36:517-519.

RAPER AB 1948 Cerebral Schistosomiasis. East African Medical fournal 25:262-263.

RosENBAum RM, IsHiI N, TANOWITZ H, et al. 1972 Schistosomiasis mansoni of the spinal cord. American fournal of Tropical Medicine and Hygiene, 21: 182-184.

Ruiz-Tiben E, Hillyer GV, KNight WB, et al. 1979 Intensity of infection with Schistosoma mansoni: its relationships to sensitivity and specificity of seriologic tests. American fournal of Tropical Medicine and Hygiene 28(2): 230-236.

SAXE N, GoRDON W 1975 Schistosomiasis of spinal cord and skin. South African Medical fournal 49:57-58.

Scaff M, Riva D, Spina-Franca A 1971 Meningorradiculomielopatia Esquistossomotica. Arquivos de Neuro Psiquiatria (Sao Paulo) 29(2):227-233.

Scully RE, MARK EJ, MCNeAly BU 1985 A 21 -year-old male with fever, diarrhoea and weakness of the legs during a sojourn in Kenya. New England Fournal of Medicine 312:13761383.

Shimamura S, Tsunoda T 1906 Pathology of so-called katayama disease. Kyoto Igaku Zasshi 2:149-175 (as cited in BIRD AV, 1965).

SidDORN JA 1965 Schistosomiasis and anterior spinal artery occlusion. American fournal of Tropical Hygiene 27(3):532-534.

SPARROW CH 1966 Bilharziasis in the human eye: report of a case. Central African fournal of Medicine 12:55.

WARREN KS 1973 The pathology of Schistosome infections. Helminthological Abstracts 42:592633.

Wilcocks C, Manson-Bahr PE 1972 Manson's Tropical Diseases. London, Balière Tindall.

Wood MG, SRolovitz H, Schetman D 1976 Schistosomiasis, paraplegia and ectopic skin lesions as admission symptoms. Archives of Dermatology 112:690-695.

World Health ORganization 1965 Snail control in the prevention of Bilharziasis. Monograph series number 50. World Health Organization Geneva, 254 p. 